\title{
Association of Depressive Symptoms with Cancer Risk in Middle- Aged and Older Chinese Adults: A Longitudinal Cohort Study
}

\section{Chao Sheng}

Tianjin Medical University Cancer Institute and Hospital

Luyang Liu

Tianjin Medical University Cancer Institute and Hospital

\section{Fengju Song}

Tianjin Medical University Cancer Institute and Hospital

Hongji Dai ( $\nabla$ daihongji@tmu.edu.cn )

Tianjin Medical University Cancer Institute and Hospital

\section{Kexin Chen}

Tianjin Medical University Cancer Institute and Hospital

\section{Research Article}

Keywords: Depression, CES-D, Cancer risk, Hormone-related cancers, Cohort study

Posted Date: December 6th, 2021

DOI: https://doi.org/10.21203/rs.3.rs-1094944/v1

License: (9) This work is licensed under a Creative Commons Attribution 4.0 International License. Read Full License 


\section{Abstract}

Aims. Although, the association between depression and cancer has already been very well studied, but studies about depressive symptoms and cancer development are scarce and inconclusive among Chinese adults. We aimed to investigate whether the severity of depressive symptoms is associated with total and site-specific cancer risk in a nationally representative sample of middle-aged and older Chinese adults.

Methods. This study was based on the China Health and Retirement Longitudinal Study (CHARLS), which was initiated in 2011 and followed up to 2018 . We included 11,974 individuals aged 45 years or older with complete information about depressive symptoms and no history of cancer at baseline. Depressive symptoms were assessed using the validated 10-item of Center for Epidemiologic Studies Depression Scale (CES-D). Incident cancer cases were documented in the biennial self-reported questionnaires. The multivariable Cox proportional hazards model was used to estimate the hazard ratios (HRs) and 95\% confidence intervals (Cls).

Results. Of 11,794 individuals included in the analysis, 51.72\% were women. After a median follow-up of 7.0 years, 265 incident cancer cases were identified. Overall, there was a significant positive association between CES-D score and cancer risk (HR 1.02, $95 \% \mathrm{Cl} 1.00-1.05, P=0.03)$. Severe depressive symptoms were associated with a $75 \%$ increased cancer risk ( $\mathrm{HR} 1.75,95 \% \mathrm{Cl} 1.10-$ 2.78). Such associations were evident among women rather than men. In the cancer-specific analysis, the association of severe depressive symptoms and cancer risk was more pronounced for female hormone-related cancers (HR 5.58; 95\% $\mathrm{Cl} 2.70-11.54)$.

Conclusions. The findings imply that individuals with severe depressive symptoms could be considered as high-risk population in cancer screening programs.

\section{Introduction}

Depressive symptoms among middle-aged and older adults are common [1]. In China, the prevalence of depressive symptoms was high (32.68\% for men and $42.81 \%$ for women, respectively) and unevenly distributed across regions and subpopulation [2]. A growing body of evidence suggested that elevated depressive symptoms were associated with increased risk of all-cause mortality, as well as incidence of various chronic diseases including obesity, hypertension, diabetes, coronary artery disease, and stroke [3-5].

It has long been speculated that people with mental disorders had a higher risk of developing certain cancers [6]. Potential psychophysiological mechanisms included dysregulation of the hypothalamic-pituitary-adrenal (HPA) axis and immune dysregulation in patients with mental disorders [7]. However, the specific association between depression and incident cancer risk remains mixed and uncertain. While some studies reported that depression was associated with an increased risk of total or sitespecific cancer [8-10], others found a null association [11, 12]. These studies varied by sample size, depression assessment method, follow-up period, and population characteristics. Previous meta-analyses suggested a small yet significant association between depression and subsequent overall cancer risk $[13,14]$. Moreover, clinically diagnosed depression and anxiety were related to a $15 \%$ increased risk of cancer incidence and $24 \%$ increased risk of cancer-specific mortality [15], which suggested a potential etiologic role and prognostic impact of depression on cancer.

Although mental disorder is a major public health concern in China, to our knowledge, there is no prospective study to investigate the association between elevated depressive symptoms and subsequent risk of cancer in mainland China. Therefore, we aim to examine whether elevated depressive symptoms could be an independent predictor of cancer in a general population of Chinese men and women, using data from the China Health and Retirement Longitudinal Study (CHARLS).

\section{Methods}

\section{Study population}

CHARLS is a nationwide, community-engaged, population-based epidemiological study of Chinese adults aged 45 years or older [16]. Briefly, the baseline survey of CHARLS was launched by the National School of Development at Peking University between June 2011 and March 2012. Using the multistage stratified probability-proportional-to-size sampling technique, a total of 17,708 individuals were recruited from 150 counties or districts and 450 villages within 28 provinces in mainland China. All participants signed informed consents and gave the permission to be interviewed using a face-to-face computer-assisted personal interview 
(CAPI). The completion rate of the baseline survey was $80.5 \%$. All respondents would be followed up and re-surveyed every 2 years after the baseline survey. Further details of the study design were available elsewhere [16].

For the current analysis, we used data from wave 1 (2011) to wave 4 (2018) of the CHARLS. We excluded 222 participants who had no answers on the study outcome, 207 participants who had history of any cancer, and 222 participants with incomplete information on depressive symptoms at baseline. Besides, we also excluded 4,173 participants with missing data on body mass index (BMI), education level, smoking and alcohol drinking habits, history of diabetes, dyslipidemia, chronic kidney disease, or hypertension. Therefore, a total of 11,974 participants were included in the present study (Figure. 1).

\section{Assessment of Depressive Symptoms}

Depressive symptoms were assessed by the questionnaire with a 10-item Center for Epidemiological Studies Depression (CES-D) scale, which was widely used in population-based studies. [17] The CES-D form consisted of 10 items: (1) felt depressed, (2) everything was an effort, (3) sleep was restless, (4) felt happy, (5) felt lonely, (6) bothered by little things, (7) could not get going, (8) had trouble concentrating, (9) felt hopeful and (10) felt fearful. These items recorded the frequency of the respondent's feelings over the week before the interview. The answers for each of the ten questions varied from "rarely or none of the time" (0-1 days), "some or a little of the time" (1-2 days), "occasionally or a moderate amount of the time" (3-4 days) to "most or all of the time" (5-7 days). Each item was scored from 0 to 3, rather than 1 to 4 . Before summing item scores, items 5 and 8 were reverse scored. The CES-D total score ranged from 0 to 30, with higher overall scores indicating more depressive symptoms. CES-D scale displayed good validity and reliability in the Chinese elderly, with the Cronbach alpha ranging from 0.78 to 0.79 [18]. According to the CES-D score, we categorized depressive symptoms as none (0-9), moderate (10-19), and severe $(\geq 20)[17,19]$.

\section{Assessment of outcome}

Information on cancer was collected through a self- or proxy-reported physician's diagnosis from wave 2 (2013), wave 3 (2015) and wave 4 (2018) of the CHARLS, and also from the Exit and Verbal Autopsy Questionnaire in 2013. The specific cancer type included: 1) Brain; 2) Oral cavity; 3) Larynx; 4) Other pharynx; 5) Thyroid; 6) Lung;7) Breast; 8) Esophagus; 9) Stomach; 10) Liver; 11) Pancreas; 12) Kidney; 13) Prostate; 14) Testicle; 15) Ovary; 16) Cervix; 17) Endometrium; 18) Colon or rectum; 19) Bladder; 20) Skin; 21) NonHodgkin lymphoma; 22) Leukemia; 23) Another location. Due to limited incidence of some cancer types, we categorized these cancers into four main groups, including respiratory cancer (laryngeal and lung cancer), gastrointestinal cancer (oral cancer, pharyngeal cancer, esophageal cancer, stomach cancer, colorectal cancer, liver cancer, biliary tract cancer and pancreatic cancer), hormone-related cancer (breast cancer, cervical cancer, uterine body cancer, and ovarian cancer) and other cancer. The date of cancer diagnosis was recorded as being between the date of the last interview and that of the interview reporting an incident cancer [20].

\section{Covariates}

Sociodemographic characteristics, lifestyle factors, and medical history were collected by trained interviewers at the baseline. Sociodemographic characteristics included age, sex, living residence (urban, rural), education level (categorized as primary school and below, middle school, high school and above), and marital status (married, unmarried). Lifestyle factors included self-reported smoking and alcohol drinking status (categorized as never, former, current). Participants were also asked about their personal history of major chronic diseases, such as hypertension, dyslipidemia, diabetes, and chronic kidney disease. Body weight and height were measured at baseline according to standardized protocols. BMI was calculated as weight in kilograms divided by height in meters squared.

\section{Statistical Analysis}

Data analysis was conducted from October 25, 2020 to February 13, 2021. The continuous variables were reported as mean (SD) and categorical variables were reported as whole numbers and proportions. Due to the complex study design applied to the CHARLS [16], we used the appropriate sample weight for reconstituting representative population-level data for the entire population. We compared baseline characteristics of depressive symptoms by using the Rao-Scott $\chi^{2}$ test for categorical variables and analysis of variance adjusted for sampling weights for continuous variables. Data were censored at date of record of cancer, death, loss to follow-up or November $31^{\text {st }} 2018$, whichever came first. We performed multivariable Cox proportional hazards models to examine the association between depressive symptoms and cancer risk with consideration of potential confounding variables. Model 1 was 
adjusted for age, sex, and living residence. Model 2 was further controlled for smoking and alcohol drinking, marital status, and educational level. In model 3, other factors such as BMI, history of diabetes, hypertension, dyslipidemia, and chronic kidney disease were added to model 2. We also examined the proportional hazard assumption by creating a cross product of follow-up time and depressive symptoms status $(P=0.19)$. In addition, we explored the potential nonlinear associations using 3-knotted restricted cubic spline regression. We further examined the associations between depressive symptoms and site-specific cancer. Sensitivity analyses were used to assess the robustness of the results. To avoid reverse causation, participants who had been diagnosed with cancer between 2011 and 2013 were excluded. All analyses were performed using R Statistical software, version 3.6 (R Foundation for Statistical Computing, Vienna, Austria) and SAS 9.4. We considered a two-tailed $P$ value $<0.05$ to be statistically significant.

\section{Results}

A total of 11,974 adults were included in the analysis. Among these participants, 6,193 (51.72\%) were women and $5781(48.28 \%)$ were men. The mean age of the study participants was 59 years. Baseline characteristics of participants according to gender and depressive symptoms were shown in Table 1. According to 10 items of CES-D, severe depressive symptoms was identified in $9.04 \%$ women and $4.55 \%$ in men, respectively. Compared with women without depressive symptoms, women with depressive symptoms appeared to be older, more likely to be lower education level, lower BMI, live in a rural setting, be smokers, and have a history of chronic kidney disease and dyslipidemia (all $P<0.05$ ). Among men, consistent pattern was seen for the association of age, $\mathrm{BMI}$, residence, educational level, and history of chronic kidney disease with depression status. Besides, men with moderate or severe depressive symptoms were more likely to be never married, former drinkers, and have a history of hypertension (all $P<0.01$ ). 
Table 1

Baseline characteristics of 11,974 participants according to depressive symptoms status and gender, $\mathrm{n}(\%)$.

\begin{tabular}{|c|c|c|c|c|c|c|c|c|}
\hline & Male & & & & Female & & & \\
\hline & No $N=4030$ & $\begin{array}{l}\text { Moderate } \\
\mathrm{N}=1488\end{array}$ & $\begin{array}{l}\text { Severe } \\
\mathrm{N}=263\end{array}$ & $P^{\#}$ & No N=3484 & $\begin{array}{l}\text { Moderate } \\
\mathrm{N}=2149\end{array}$ & $\begin{array}{l}\text { Severe } \\
\mathrm{N}=560\end{array}$ & $P^{\#}$ \\
\hline $\begin{array}{l}\text { Age, mean } \\
\text { (SD), years }\end{array}$ & $58.97(9.21)$ & $60.51(9.42)$ & $60.48(8.97)$ & $<0.01$ & 57.68(9.37) & $59.18(9.53)$ & $60.97(9.42)$ & $<0.01$ \\
\hline $\begin{array}{l}\text { BMI, mean } \\
\text { (SD) }\end{array}$ & 23.27(3.69) & 22.33(3.60) & $22.40(3.52)$ & $<0.01$ & 24.33(4.14) & $23.55(4.02)$ & $23.29(4.20)$ & $<0.01$ \\
\hline Residence & & & & $<0.01$ & & & & $<0.01$ \\
\hline Rural & $2441(60.57)$ & 1054(70.83) & $200(76.05)$ & & 1945(55.83) & $1428(66.45)$ & 430(76.79) & \\
\hline Urban & 1589(39.43) & $434(29.17)$ & $63(23.95)$ & & 1539(44.17) & 721(33.55) & $130(23.21)$ & \\
\hline $\begin{array}{l}\text { Education } \\
\text { level }\end{array}$ & & & & $<0.01$ & & & & $<0.01$ \\
\hline $\begin{array}{l}<=\text { Primary } \\
\text { school }\end{array}$ & $2177(54.02)$ & 1014(68.15) & 197(74.90) & & 2476(71.07) & 1779(82.78) & 492(87.86) & \\
\hline $\begin{array}{l}\text { Middle } \\
\text { school }\end{array}$ & 1131(28.06) & $344(23.12)$ & $53(20.15)$ & & 646(18.54) & $273(12.70)$ & $52(9.29)$ & \\
\hline $\begin{array}{l}\text { >=high } \\
\text { school }\end{array}$ & 722(17.92) & 130(8.74) & $13(4.94)$ & & $362(10.39)$ & $97(4.51)$ & 16(2.86) & \\
\hline $\begin{array}{l}\text { Marital } \\
\text { status }\end{array}$ & & & & $<0.01$ & & & & 0.63 \\
\hline Married & 3992(99.06) & 1445(97.11) & 257(97.72) & & 3482(99.94) & 2148(99.95) & $560(100.00)$ & \\
\hline $\begin{array}{l}\text { Never } \\
\text { Married }\end{array}$ & $38(0.94)$ & $43(2.89)$ & $6(2.28)$ & & $2(0.06)$ & $1(0.05)$ & $0(0.00)$ & \\
\hline Smoking & & & & 0.33 & & & & 0.02 \\
\hline Never & 1049(26.03) & $329(22.11)$ & $69(26.24)$ & & $3217(92.34)$ & 1964(91.39) & 499(89.11) & \\
\hline Former & $661(16.40)$ & $241(16.20)$ & $36(13.69)$ & & $70(2.01)$ & $49(2.28)$ & $16(2.86)$ & \\
\hline Current & $2320(57.57)$ & $918(61.69)$ & $158(60.08)$ & & 197(5.65) & $136(6.33)$ & $45(8.04)$ & \\
\hline $\begin{array}{l}\text { Alcohol } \\
\text { drinking }\end{array}$ & & & & $<0.01$ & & & & 0.10 \\
\hline Never & 1236(30.67) & $505(33.94)$ & $80(30.42)$ & & 2967(85.16) & 1767(82.22) & $460(82.14)$ & \\
\hline Former & $441(10.94)$ & $228(15.32)$ & $55(20.91)$ & & 119(3.42) & $111(5.17)$ & $31(5.54)$ & \\
\hline Current & 2353(58.39) & $755(50.74)$ & $128(48.67)$ & & 398(11.42) & 271(12.61) & $69(12.32)$ & \\
\hline Hypertension & & & & $<0.01$ & & & & 0.12 \\
\hline No & $3187(79.08)$ & 1129(75.87) & 192(73.00) & & $2624(75.32)$ & 1548(72.03) & 417(74.46) & \\
\hline Yes & $843(20.92)$ & $359(24.13)$ & $71(27.00)$ & & $860(24.68)$ & 601(27.97) & $143(25.54)$ & \\
\hline Dyslipidemia & & & & 0.68 & & & & 0.03 \\
\hline No & $3690(91.56)$ & 1364(91.67) & 245(93.16) & & 3182(91.33) & 1919(89.30) & 494(88.21) & \\
\hline Yes & $340(8.44)$ & 124(8.33) & 18(6.84) & & $302(8.67)$ & $230(10.70)$ & 66(11.79) & \\
\hline
\end{tabular}

\#For categorical variables, $P$ value was calculated by Rao-Scott $\chi^{2}$ test. For continuous variables, variance analysis adjusted sampling weights were used to calculate $P$ value. 


\begin{tabular}{|c|c|c|c|c|c|c|c|c|}
\hline & \multicolumn{4}{|l|}{ Male } & \multicolumn{4}{|l|}{ Female } \\
\hline & No $N=4030$ & $\begin{array}{l}\text { Moderate } \\
\mathrm{N}=1488\end{array}$ & $\begin{array}{l}\text { Severe } \\
\mathrm{N}=263\end{array}$ & $P^{\#}$ & No $N=3484$ & $\begin{array}{l}\text { Moderate } \\
\mathrm{N}=2149\end{array}$ & $\begin{array}{l}\text { Severe } \\
\mathrm{N}=560\end{array}$ & $P^{\#}$ \\
\hline Diabetes & & & & 0.04 & & & & 0.21 \\
\hline No & $3847(95.46)$ & 1402(94.22) & $248(94.30)$ & & $3275(94.00)$ & 1991(92.65) & $518(92.50)$ & \\
\hline Yes & $183(4.54)$ & $86(5.78)$ & $15(5.70)$ & & $209(6.00)$ & 158(7.35) & $42(7.50)$ & \\
\hline $\begin{array}{l}\text { Chronic } \\
\text { kidney } \\
\text { disease }\end{array}$ & & & & $<0.01$ & & & & $<0.01$ \\
\hline No & $3806(94.44)$ & 1343(90.26) & $220(83.65)$ & & $3355(96.30)$ & 2013(93.67) & $486(86.79)$ & \\
\hline Yes & $224(5.56)$ & 145(9.74) & $43(16.35)$ & & 129(3.70) & $136(6.33)$ & $74(13.21)$ & \\
\hline
\end{tabular}

After a median follow-up of 7.0 years, 149 incident cancer cases were identified in men and 116 in women. The incidence rate of cancer was 3.89 per 1000 person-years among women and 3.34 per 1000 person-years among men. Overall, after adjusting for age, sex, residence, marital status, educational level, smoking and alcohol drinking, BMI and other confounders, the CES-D score were weakly but positively associated with cancer risk (HR 1.02, 95\% Cl 1.00-1.05, $P=0.03$, Table 2 ). When the depressive symptoms were categorized into three groups, compared to individuals without depressive symptoms (CES-D score < 10), those with severe depressive symptoms (CES-D score $\geq 20$ ) were associated with a $75 \%$ increased risk of overall cancer (adjusted $\mathrm{HR} 1.75 ; 95 \% \mathrm{Cl}$ 1.10-2.75, Table 2, Model3). For women, the adjusted HR (95\% Cl) for incident cancer was 1.44 (1.00-2.07) for moderate depressive symptoms, and 2.50 (1.38-4.54) for severe depressive symptoms ( $P$ for trend<0.01). For men, however, there is no significant association between depressive symptoms and the risk of overall cancer. The association between depressive symptoms and incident cancer did not change substantially in the sensitivity analyses (Supplemental Table 1). 
Table 2

Hazard ratio (HRs) and 95\% confidence intervals (Cls) for risk of cancer by different depressive symptoms status

\begin{tabular}{|c|c|c|c|c|c|}
\hline \multirow[t]{2}{*}{ Outcome } & \multirow{2}{*}{$\begin{array}{l}\text { Case. } \\
\text { No }\end{array}$} & \multirow{2}{*}{$\begin{array}{l}\text { Incidence rate, per } 1000 \text { Person- } \\
\text { years }\end{array}$} & \multicolumn{3}{|l|}{$\mathrm{HR}(95 \% \mathrm{Cl})$ * } \\
\hline & & & Model $1^{\mathrm{a}}$ & Model $2^{b}$ & Model $3^{c}$ \\
\hline \multicolumn{6}{|l|}{ All participants } \\
\hline CES-D score & 265 & 3.62 & $\begin{array}{l}1.02(1.00-1.05) \\
\#\end{array}$ & $\begin{array}{l}1.02(1.00-1.05) \\
\#\end{array}$ & $\begin{array}{l}1.02(1.00- \\
1.05)^{\#}\end{array}$ \\
\hline \multicolumn{6}{|l|}{$\begin{array}{l}\text { Depressive } \\
\text { symptoms }\end{array}$} \\
\hline No $(<10)$ & 154 & 3.34 & 1 & 1 & 1 \\
\hline Moderate (10-19) & 83 & 3.75 & $1.02(0.78-1.35)$ & $1.01(0.76-1.33)$ & $1.03(0.78-1.36)$ \\
\hline Severe $(>=20)$ & 28 & 5.75 & $1.77(1.13-2.76)$ & $1.73(1.10-2.71)$ & $1.75(1.10-2.78)$ \\
\hline$P$ for trend & & & 0.07 & 0.09 & 0.07 \\
\hline \multicolumn{6}{|l|}{ Female } \\
\hline CES-D score & 149 & 3.89 & $1.05(1.02-1.08)$ & $1.05(1.02-1.08)$ & $1.05(1.02-1.08)$ \\
\hline \multicolumn{6}{|l|}{$\begin{array}{l}\text { Depressive } \\
\text { symptoms }\end{array}$} \\
\hline No $(<10)$ & 70 & 3.23 & 1 & 1 & 1 \\
\hline Moderate (10-19) & 58 & 4.36 & $1.41(0.99-2.02)$ & $1.42(0.99-2.04)$ & $\begin{array}{l}1.44(1.00-2.07) \\
\#\end{array}$ \\
\hline Severe $(>=20)$ & 21 & 6.25 & $2.47(1.40-4.37)$ & $2.47(1.39-4.4)$ & $2.50(1.38-4.54)$ \\
\hline$P$ for trend & & & $<0.01$ & $<0.01$ & $<0.01$ \\
\hline \multicolumn{6}{|l|}{ Male } \\
\hline CES-D score & 116 & 3.34 & $0.99(0.96-1.02)$ & $0.99(0.95-1.02)$ & $0.99(0.96-1.02)$ \\
\hline \multicolumn{6}{|l|}{$\begin{array}{l}\text { Depressive } \\
\text { symptoms }\end{array}$} \\
\hline No $(<10)$ & 84 & 3.44 & 1 & 1 & 1 \\
\hline Moderate (10-19) & 25 & 2.83 & $0.65(0.39-1.06)$ & $0.63(0.38-1.03)$ & $0.65(0.40-1.06)$ \\
\hline Severe $(>=20)$ & 7 & 4.64 & $1.11(0.51-2.41)$ & $1.06(0.49-2.29)$ & $1.09(0.50-2.35)$ \\
\hline$P$ for trend & & & 0.33 & 0.27 & 0.32 \\
\hline \multicolumn{6}{|c|}{ *All estimates accounted for complex survey designs. } \\
\hline \multicolumn{6}{|l|}{${ }^{\#} P<0.05$} \\
\hline \multicolumn{6}{|c|}{ a Model 1 was adjusted for age, sex and residence. } \\
\hline \multicolumn{6}{|c|}{ b Model 2 was adjusted for age, sex, residence, marital status, educational level, smoking status, and alcohol drinking status. } \\
\hline
\end{tabular}

As shown in Figure 2, we observed a linear trend between CES-D total score and subsequent cancer risk using restricted cubic spline regression in women $(P$ for overall<0.01, $P$ for nonlinearity $=0.78$; Figure $2 B$ ) but not in men $(P$ for overall $=0.93, P$ for nonlinearity $=0.87$; Figure $2 \mathrm{C}$ ). 
Figure 3 shows the association between specific depressive symptoms and incident cancer. When all 10 specific depressive symptoms as measured by the CES-D items in model 3, women who have four symptoms (felt depressed: adjusted $\mathrm{HR} 1.81 ; 95 \% \mathrm{Cl}$ 1.10-2.98; felt everything was an effort: adjusted HR 2.1; 95\% Cl 1.31-3.36; felt fearful: adjusted HR 3.61; 95\% Cl 2.22-5.89; sleep was restless: adjusted HR $1.62 ; 95 \% \mathrm{Cl} 1.07-2.45)$ most or all of the time were more likely to develop cancer than women without four symptoms during the last week. There is no significant association between specific depressive symptoms and cancer risk among men.

The most common cancer types in the CHARLS were gastrointestinal cancer $(N=94)$, hormone-related cancer $(n=69)$ and respiratory cancer $(n=42)$. Among these major cancer types, we found elevated depressive symptoms were associated with an increased risk of hormone-related cancer ( $P$ for trend<0.01). Severe depressive symptoms were significantly associated with increased risk of hormone-related cancer in women (HR 5.58, 95\% Cl 2.70-11.54). We found no significant association between depressive symptoms and gastrointestinal cancers, gynecological cancers, and other cancers in women and men (Table 3 ). 
Table 3

Association between depressive symptoms and risk of site-specific cancer in women and men*

\begin{tabular}{|c|c|c|c|c|}
\hline & \multicolumn{3}{|c|}{ Depressive symptoms } & \multirow[t]{2}{*}{$P$ for trend } \\
\hline & No & Moderate & Severe & \\
\hline \multicolumn{5}{|l|}{ Female } \\
\hline \multicolumn{5}{|c|}{ Respiratory cancer } \\
\hline Case. No & 7 & 7 & 2 & \\
\hline Incidence rate & 0.33 & 0.53 & 0.61 & \\
\hline Model $1^{\mathrm{a}}$ & 1 & $1.14(0.39-3.39)$ & $1.01(0.21-4.88)$ & 0.88 \\
\hline Model $2^{b}$ & 1 & $1.17(0.40-3.38)$ & $1.00(0.21-0.47)$ & 0.87 \\
\hline Model $3^{c}$ & 1 & $1.11(0.37-3.32)$ & $0.96(0.19-4.91)$ & 0.95 \\
\hline \multicolumn{5}{|c|}{ Gastrointestinal cancer } \\
\hline Case. No & 13 & 16 & 5 & \\
\hline Incidence rate & 0.61 & 1.22 & 1.51 & \\
\hline Model $1^{a}$ & 1 & $1.98(0.94-4.17)$ & $2.68(0.90-7.98)$ & 0.03 \\
\hline Model $2^{b}$ & 1 & $1.98(0.91-4.30)$ & $2.65(0.85-8.24)$ & 0.04 \\
\hline Model $3^{c}$ & 1 & $1.93(0.89-4.16)$ & $2.52(0.80-7.93)$ & 0.046 \\
\hline \multicolumn{5}{|c|}{ hormone-related cancer } \\
\hline Case. No & 32 & 24 & 13 & \\
\hline Incidence rate & 1.48 & 1.82 & 3.89 & \\
\hline Model $1^{\mathrm{a}}$ & 1 & $1.59(0.93-2.73)$ & $5.20(2.54-10.66)$ & $<0.01$ \\
\hline \multirow[t]{2}{*}{ Model $2^{b}$} & 1 & $1.59(0.92-2.76)$ & $5.23(2.50-10.96)$ & $<0.01$ \\
\hline & 1 & $1.66(0.96-2.87)$ & $5.58(2.70-11.54)$ & $<0.01$ \\
\hline \multicolumn{5}{|l|}{ Model $3^{c}$} \\
\hline \multicolumn{5}{|l|}{ Other cancer } \\
\hline \multicolumn{5}{|c|}{ *All estimates accounted for complex survey designs } \\
\hline \multicolumn{5}{|c|}{ a Model 1 was adjusted for age, sex and residence } \\
\hline \multicolumn{5}{|c|}{ b Model 2 was adjusted for age, sex, residence, marital status, educational level, smoking status, and drinking status } \\
\hline \multicolumn{5}{|c|}{$\begin{array}{l}\text { c Model } 3 \text { was adjusted as model } 2 \text { plus body mass index; history of diabetes, hypertension, dyslipidemia, and chronic kidne } \\
\text { disease }\end{array}$} \\
\hline
\end{tabular}




\begin{tabular}{|c|c|c|c|c|}
\hline Case. No & 18 & 12 & 1 & \\
\hline Incidence rate & 0.84 & 0.91 & 0.30 & \\
\hline Model $1^{\text {a }}$ & 1 & $1.03(0.50-2.16)$ & $0.16(0.02-1.23)$ & 0.33 \\
\hline Model $2^{b}$ & 1 & $1.01(0.49-2.08)$ & $0.15(0.02-1.23)$ & 0.29 \\
\hline Model $3^{c}$ & 1 & $1.00(0.49-2.04)$ & $0.12(0.01-1.05)$ & 0.19 \\
\hline \multicolumn{5}{|l|}{ Male } \\
\hline \multicolumn{5}{|c|}{ Respiratory cancer } \\
\hline Case. No & 19 & 6 & 1 & \\
\hline Incidence rate & 0.78 & 0.68 & 0.67 & \\
\hline Model $1^{a}$ & 1 & $0.94(0.35-2.52)$ & $0.64(0.08-4.84)$ & 0.74 \\
\hline Model $2^{b}$ & 1 & $0.93(0.35-2.50)$ & $0.67(0.09-4.81)$ & 0.74 \\
\hline Model $3^{c}$ & 1 & $0.95(0.36-2.49)$ & $0.63(0.09-4.55)$ & 0.73 \\
\hline \multicolumn{5}{|c|}{ Gastrointestinal cancer } \\
\hline Case. No & 44 & 12 & 4 & \\
\hline Incidence rate & 1.81 & 1.36 & 2.67 & \\
\hline Model 1 a & 1 & $0.47(0.25-0.88)$ & $1.11(0.40-3.09)$ & 0.24 \\
\hline Model $2^{b}$ & 1 & $0.46(0.24-0.86)$ & $1.08(0.39-3.02)$ & 0.22 \\
\hline Model $3^{c}$ & 1 & $0.49(0.26-0.92)$ & $1.19(0.43-3.36)$ & 0.31 \\
\hline \multicolumn{5}{|l|}{ Other cancer } \\
\hline Case. No & 21 & 6 & 2 & \\
\hline Incidence rate & 0.87 & 0.68 & 1.34 & \\
\hline
\end{tabular}

*All estimates accounted for complex survey designs

a Model 1 was adjusted for age, sex and residence

${ }^{b}$ Model 2 was adjusted for age, sex, residence, marital status, educational level, smoking status, and drinking status

${ }^{c}$ Model 3 was adjusted as model 2 plus body mass index; history of diabetes, hypertension, dyslipidemia, and chronic kidney disease 


\begin{tabular}{|c|c|c|c|c|}
\hline & \multicolumn{3}{|c|}{ Depressive symptoms } & \multirow[t]{2}{*}{$P$ for trend } \\
\hline & No & Moderate & Severe & \\
\hline Model $1^{\mathrm{a}}$ & 1 & $0.72(0.28-1.89)$ & $1.53(0.35-6.76)$ & 0.93 \\
\hline Model $2^{b}$ & 1 & $0.66(0.25-1.72)$ & $1.31(0.31-5.64)$ & 0.75 \\
\hline Model $3^{c}$ & 1 & $0.67(0.26-1.71)$ & $1.28(0.29-5.59)$ & 0.75 \\
\hline \multicolumn{5}{|c|}{ *All estimates accounted for complex survey designs } \\
\hline \multicolumn{5}{|c|}{${ }^{a}$ Model 1 was adjusted for age, sex and residence } \\
\hline \multicolumn{5}{|c|}{ b Model 2 was adjusted for age, sex, residence, marital status, educational level, smoking status, and drinking status } \\
\hline
\end{tabular}

\section{Discussion}

To our knowledge, our study is the first to prospectively investigate the association between depressive symptoms and subsequent cancer risk in mainland China. In this population-based, nationally representative longitudinal cohort of 11,974 Chinese adults, we found that a high CES-D score and severe depressive symptoms were independently associated with increased cancer risk. Overall cancer morbidity was positively associated with depression in women but not in men. The association of depressive symptoms and cancer risk was more pronounced for female hormone-related cancers.

It was reported that clinically diagnosed depression was more likely to be associated with subsequent cancer risk than elevated depressive symptoms [15]. Clinically diagnosed depression, also known as major depression or major depressive disorder (MDD), is the most severe form of depression. It is characterized by depressed mood, diminished interests, impaired cognitive function, and vegetative symptoms [21]. Previous studies found a positive association between clinical depression and cancer incidence [22, 23]. However, it remains debatable whether depressive symptoms associated with cancer development [12, 24]. In our study, when CES-D score was treated as a continuous variable, it suggested a small but significant association between depressive symptoms and subsequent overall cancer risk. When we used a cut-off CES-D score of 10 and 20 to define moderate and severe depressive symptoms, which offered a more stringent approach to the classification of depressive symptoms, we found severe depressive symptoms were associated with a $75 \%$ increased cancer risk. This result was similar with a previous U.S. study [25], which suggested that a certain threshold of severe depressive symptoms might exist in the relation of depression and subsequent cancer. Thus, in our study, this may explain that severe depressive symptoms, rather than moderate depressive symptoms, were significantly associated with overall cancer risk. Individuals with severe depressive symptoms, who were always ignored and unnoticed for years, were more likely to develop clinical depression. Although increased cancer risks were found for patients with depression, most cancer screening programs excluded people with mental illness. Thus, we suggest that individuals with very high depressive symptoms could be considered as high-risk population in cancer screening programs.

We found a positive association and a dose-response relationship between depressive symptoms and cancer risk among women, while a null association among man, which is inconsistent with a previous South Korean study [26], This discrepancy can be explained by the differences in study methods and settings. The gender difference in the present study may result from gender differences in unmeasured factors such as biological mechanisms, including the immune system. Interestingly, there is evidence suggesting women could be more vulnerable to inflammation-induced depression [27]. Thus, depression or severe depressive symptoms may be associated with cancer incidence to a greater extent in women than in men. Besides, it could possibly be attributable to menopausal transition in women's life. The changed level of sex hormones could be related to both cancer and depression $[28,29]$.

This study found that restless sleep, depression, stress, and fear were significantly with cancer risk among women. Compared with women whose sleep were restless rarely or none of the time, women with restless sleep most or all of the time during the last week were more likely to develop cancer. A recent study suggests that poor sleep quality is significantly associated with the risk of 
subsequent cancer, especially for women, at 8-year follow-up [20]. The mechanisms included reduction in production of melatonin, sleep disruption, and lifestyle disturbance. When living with a lot of stress, people would feel everything did was an effort. Studies in animals and human have suggested that stress and depression may lead to an impairment of the immune response and might promote the initiation and progression of some types of cancer [7]. Literature on the effect of fear on cancer is even scarcer. However, fear itself may affect behavior, although its behavioral effects are not yet clear. Some studies have shown that people are more afraid of cancer than any other diseases, and suggested that it prevents help-seeking and screening for cancers [30], and others have shown that it has a motivating effect [31, 32].

Among specific cancer types, we found severe depressive symptoms were significantly associated with an increased risk of hormone-related cancers among women. There is more evidence to support the hypothesis that cancers are not biologically homogenous, and as such depression may influence different types of cancer in different ways [7]. Previous studies also indicated that depression was associated with an increased cancer risk of lung, prostate, and a decreased cancer risk of cervical [22, 26]. It is worth noting that our study found an increased risk of hormone-related cancers. Although some previous studies didn't report significant associations between depression and hormone-related cancers [10, 11, 33, 34], several studies identified a significant association between depression and hormone-sensitive cancers, including breast, ovarian, uterus, cervical, and prostate cancers [8, $25,26,35]$. The different results across studies may be attributable to patient heterogeneity, cultural factors, socio-economic levels, and the state of medical care [36]. In addition, various prevalence of depression and cancer among countries may also affect the estimate of the association between depression and cancer risk [14].

Several mechanisms may be responsible for the association between depression and subsequent cancer development. One plausible pathway involves the hypothalamic-pituitary-adrenal (HPA) axis. The persistent activation of the HPA axis and exorbitant levels of cortisol in the chronic stress response and depression probably impairs the immune response and contributes to the development and progression of cancer [7,37]. Changes in the secretion and regulation of cytokines could be another possible pathway through which exposure to depression may be associated with incident cancer risk. It found that patients with MDD had increased serum levels of cytokines, such as tumor necrosis factor (TNF) and IL-6 [38]. It is well established that TNF and IL-6 promote tumor development through direct effects on premalignant cells and by orchestrating a tumor-promoting microenvironment through effects on many different cell types [39].

To our knowledge, this is the first study to prospectively investigate the association between total CES-D score, individual depressive symptoms and subsequent cancer risk in mainland China. The strength of this study included prospective and complex survey design and statistical control for many confounding information. Due to the multistage stratified probability-proportional-to-size sampling technique, the sample can be fully to represent Chinese adults aged 45 and above. There are also limitations to be noted. First, we used a self-reported questionnaire to ascertain depression status and cancer cases, thus there may be misclassifications. In order to reduce this bias, we confirmed the incident cancer cases through surveys of wave 2 and wave 3 . Second, our study has a limited follow-up period of about 7 years. We cannot investigate the long-term cumulative effect of depression on cancer development. Third, our study is limited by small number of site-specific cancers. Finally, although we adjusted for the sociodemographic characteristics, lifestyle factors, and medical history in the study, residual confounding is still possible.

In summary, we found severe depressive symptoms were significantly associated with incident cancer risk among Chinese adults, especially for women. Further investigations are warranted to validate the result and understand the underlying mechanisms.

\section{Declarations}

\section{Acknowledgements}

We would like to thank the China Health and Retirement Longitudinal Study (CHARLS) for providing data. The statements contained herein are solely those of the authors and do not represent or imply concurrence or endorsement by CHARLS.

\section{Authors' contributions}

SC and LL performed data extractions, analyzed the results, and wrote the manuscript. DH, SF-J, and CK-X revised and edited the manuscript. All authors made substantial contributions to the acquisition of data, analysis and interpretation of data, all authors have been involved in revising and critically evaluating the manuscript for important intellectual content. In addition, each author has 
agreed to be accountable for the accuracy and integrity of this research work. All authors contributed to the article and approved the submitted version.

\section{Funding}

This work was supported by Beijing-Tianjin-Hebei Basic Research Cooperation Special Project (No. 20JCZXJC00090), the National Natural Science Foundation of China (81974439) and Tianjin Science and Technology Committee Foundation (18YFZCSY00520).

\section{Availability of data and materials}

The dataset supporting the conclusions of this article are available from the Harmonized China Health and Retirement Longitudinal Study (CHARLS) dataset (http://charls.pku.edu.cn/index/en.html) and Codebook, version C, as of April 2018, which was developed by the Gateway to Global Aging Data (https:/g2aging.org).

\section{Ethics approval and consent to participate}

The current study is a secondary analysis of CHARLS public data. Ethical approval for all the CHARLS waves was granted from the Institutional Review Board at Peking University. And each respondent who agreed to participate in the survey was asked to sign two copies of the informed consent. All procedures performed in the studies involving human participants were in accordance with the ethical standards of the institutional and/or national research committee and with the 1964 Helsinki declaration and its later amendments or comparable ethical standards. SC received permission from the CHARLS team to use this data.

\section{Consent for publication}

Not applicable

\section{Competing interests}

The authors declare that they have no conflict of interest.

\section{Author's details}

Department of Epidemiology and Biostatistics, National Clinical Research Center for Cancer, Key Laboratory of Molecular Cancer Epidemiology of Tianjin, Tianjin Medical University Cancer Institute and Hospital, Tianjin Medical University, Tianjin, China.

\section{References}

1. Zhang L, Xu Y, Nie H, Zhang Y, Wu Y: The prevalence of depressive symptoms among the older in China: a meta-analysis. Int $\mathrm{J}$ Geriatr Psychiatry 2012; 27(9):900-906.https://doi.org/10.1002/gps.2821.

2. Qin X, Wang S, Hsieh C-R: The prevalence of depression and depressive symptoms among adults in China: Estimation based on a National Household Survey. China Economic Review 2018; 51:271-282.https://doi.org/10.1016/j.chieco.2016.04.001.

3. Cui Y, Zheng W, Steinwandel M, Cai H, Sanderson M, Blot W, Shu XO: Associations of Depressive Symptoms With All-Cause and Cause-Specific Mortality by Race in a Population of Low Socioeconomic Status: A Report From the Southern Community Cohort Study. Am J Epidemiol 2021; 190(4):562-575.https://doi.org/10.1093/aje/kwaa216.

4. Cho IY, Chang Y, Sung E, Kang JH, Wild SH, Byrne CD, Shin H, Ryu S: Depression and increased risk of non-alcoholic fatty liver disease in individuals with obesity. Epidemiol Psychiatr Sci 2021; 30:e23.https://doi.org/10.1017/S204579602000116X.

5. Li H, Zheng D, Li Z, Wu Z, Feng W, Cao X, Wang J, Gao Q, Li X, Wang W et al: Association of Depressive Symptoms With Incident Cardiovascular Diseases in Middle-Aged and Older Chinese Adults. JAMA Netw Open 2019; 2(12):e1916591.https://doi.org/10.1001/jamanetworkopen.2019.16591.

6. Spiegel D, Giese-Davis J: Depression and cancer: mechanisms and disease progression. Biological Psychiatry 2003; 54(3):269282.https://doi.org/10.1016/s0006-3223(03)00566-3.

7. Reiche EM, Nunes SO, Morimoto HK: Stress, depression, the immune system, and cancer. Lancet Oncol 2004; 5(10):617625.https://doi.org/10.1016/s1470-2045(04)01597-9. 
8. Gross AL, Gallo JJ, Eaton WW: Depression and cancer risk: 24 years of follow-up of the Baltimore Epidemiologic Catchment Area sample. Cancer Causes Control 2010; 21(2):191-199.https://doi.org/10.1007/s10552-009-9449-1.

9. Chen YH, Lin HC: Increased risk of cancer subsequent to severe depression-a nationwide population-based study. J Affect Disord 2011; 131(1-3):200-206.https://doi.org/10.1016/j.jad.2010.12.006.

10. Goldacre MJ, Wotton CJ, Yeates D, Seagroatt V, Flint J: Cancer in people with depression or anxiety: record-linkage study. Soc Psychiatry Psychiatr Epidemiol 2007; 42(9):683-689.https://doi.org/10.1007/s00127-007-0211-2.

11. Liang JA, Sun LM, Muo CH, Sung FC, Chang SN, Kao CH: The analysis of depression and subsequent cancer risk in Taiwan. Cancer Epidemiol Biomarkers Prev 2011; 20(3):473-475.https://doi.org/10.1158/1055-9965.EPI-10-1280.

12. Lemogne C, Consoli SM, Melchior M, Nabi H, Coeuret-Pellicer M, Limosin F, Goldberg M, Zins M: Depression and the risk of cancer: a 15-year follow-up study of the GAZEL cohort. Am J Epidemiol 2013; 178(12):17121720.https://doi.org/10.1093/aje/kwt217.

13. Oerlemans ME, van den Akker M, Schuurman AG, Kellen E, Buntinx F: A meta-analysis on depression and subsequent cancer risk. Clin Pract Epidemiol Ment Health 2007; 3:29.https://doi.org/10.1186/1745-0179-3-29.

14. Jia Y, Li F, Liu YF, Zhao JP, Leng MM, Chen L: Depression and cancer risk: a systematic review and meta-analysis. Public Health 2017; 149:138-148.https://doi.org/10.1016/j.puhe.2017.04.026.

15. Wang YH, Li JQ, Shi JF, Que JY, Liu JJ, Lappin JM, Leung J, Ravindran AV, Chen WQ, Qiao YL et al: Depression and anxiety in relation to cancer incidence and mortality: a systematic review and meta-analysis of cohort studies. Mol Psychiatry 2020; 25(7):1487-1499.https://doi.org/10.1038/s41380-019-0595-x.

16. Zhao Y, Hu Y, Smith JP, Strauss J, Yang G: Cohort profile: the China Health and Retirement Longitudinal Study (CHARLS). Int J Epidemiol 2014; 43(1):61-68.https://doi.org/10.1093/ije/dys203.

17. Andresen EM, Malmgren JA, Carter WB, Patrick DL: Screening for depression in well older adults: evaluation of a short form of the CES-D (Center for Epidemiologic Studies Depression Scale). Am J Prev Med 1994; 10(2):77-84

18. Boey KW: Cross-validation of a short form of the CES-D in Chinese elderly. Int J Geriatr Psychiatry 1999; 14(8):608617.https://doi.org/10.1002/(sici)1099-1166(199908)14:8<608::aid-gps991>3.0.co;2-z.

19. Lyness JM, Noel TK, Cox C, King DA, Conwell Y, Caine ED: Screening for depression in elderly primary care patients. A comparison of the Center for Epidemiologic Studies-Depression Scale and the Geriatric Depression Scale. Arch Intern Med 1997; 157(4):449-454

20. Song C, Zhang R, Wang C, Fu R, Song W, Dou K, Wang S: Sleep quality and risk of cancer: findings from the English longitudinal study of aging. Sleep 2021; 44(3).https://doi.org/10.1093/sleep/zsaa192.

21. Belmaker RH, Agam G: Major depressive disorder. N Engl J Med 2008; 358(1):55-68.https://doi.org/10.1056/NEJMra073096.

22. Friedman GD: Psychiatrically-diagnosed depression and subsequent cancer. Cancer Epidemiol Biomarkers Prev 1994; 3(1):1113

23. O'Neill S, Posada-Villa J, Medina-Mora ME, Al-Hamzawi AO, Piazza M, Tachimori H, Hu C, Lim C, Bruffaerts R, Lepine JP et al: Associations between DSM-IV mental disorders and subsequent self-reported diagnosis of cancer. J Psychosom Res 2014; 76(3):207-212.https://doi.org/10.1016/j.jpsychores.2013.12.012.

24. Archer G, Pikhart H, Head J: Do depressive symptoms predict cancer incidence?: 17-year follow-up of the Whitehall II study. J Psychosom Res 2015; 79(6):595-603.https://doi.org/10.1016/j.jpsychores.2015.07.011.

25. Penninx BW, Guralnik JM, Pahor M, Ferrucci L, Cerhan JR, Wallace RB, Havlik RJ: Chronically depressed mood and cancer risk in older persons. J Natl Cancer Inst 1998; 90(24):1888-1893.https://doi.org/10.1093/jnci/90.24.1888.

26. Chang HY, Keyes KM, Mok Y, Jung KJ, Shin YJ, Jee SH: Depression as a risk factor for overall and hormone-related cancer: the Korean cancer prevention study. J Affect Disord 2015; 173:1-8.https://doi.org/10.1016/j.jad.2014.10.064.

27. Derry HM, Padin AC, Kuo JL, Hughes S, Kiecolt-Glaser JK: Sex Differences in Depression: Does Inflammation Play a Role? Curr Psychiatry Rep 2015; 17(10):78.https://doi.org/10.1007/s11920-015-0618-5.

28. Slavich GM, Sacher J: Stress, sex hormones, inflammation, and major depressive disorder: Extending Social Signal Transduction Theory of Depression to account for sex differences in mood disorders. Psychopharmacology (Berl) 2019; 236(10):30633079.https://doi.org/10.1007/s00213-019-05326-9. 
29. Folkerd EJ, Dowsett M: Influence of sex hormones on cancer progression. J Clin Oncol 2010; 28(26):40384044.https://doi.org/10.1200/JC0.2009.27.4290.

30. Hay JL, Buckley TR, Ostroff JS: The role of cancer worry in cancer screening: a theoretical and empirical review of the literature. Psychooncology 2005; 14(7):517-534.https://doi.org/10.1002/pon.864.

31. Andersen MR, Peacock S, Nelson J, Wilson S, Mclntosh M, Drescher C, Urban N: Worry about ovarian cancer risk and use of ovarian cancer screening by women at risk for ovarian cancer. Gynecol Oncol 2002; 85(1):38.https://doi.org/10.1006/gyno.2001.6556.

32. McCaul KD, Schroeder DM, Reid PA: Breast cancer worry and screening: some prospective data. Health Psychol 1996; 15(6):430-433.https://doi.org/10.1037//0278-6133.15.6.430.

33. Dalton SO, Mellemkjaer L, Olsen JH, Mortensen PB, Johansen C: Depression and cancer risk: a register-based study of patients hospitalized with affective disorders, Denmark, 1969-1993. Am J Epidemiol 2002; 155(12):10881095.https://doi.org/10.1093/aje/155.12.1088.

34. Reeves KW, Okereke OI, Qian J, Tamimi RM, Eliassen AH, Hankinson SE: Depression, Antidepressant Use, and Breast Cancer Risk in Pre- and Postmenopausal Women: A Prospective Cohort Study. Cancer Epidemiol Biomarkers Prev 2018; 27(3):306314.https://doi.org/10.1158/1055-9965.EPI-17-0707.

35. Huang T, Poole EM, Okereke OI, Kubzansky LD, Eliassen AH, Sood AK, Wang M, Tworoger SS: Depression and risk of epithelial ovarian cancer: Results from two large prospective cohort studies. Gynecol Oncol 2015; 139(3):481 486.https://doi.org/10.1016/j.ygyno.2015.10.004.

36. Lund C, Breen A, Flisher AJ, Kakuma R, Corrigall J, Joska JA, Swartz L, Patel V: Poverty and common mental disorders in low and middle income countries: A systematic review. Soc Sci Med 2010; 71(3):517528.https://doi.org/10.1016/j.socscimed.2010.04.027.

37. Plotsky PM, Owens MJ, Nemeroff CB: Psychoneuroendocrinology of depression: hypothalamic-pituitary-adrenal axis. Psychiatric Clinics of North America 1998; 21(2):293-307

38. Dowlati Y, Herrmann N, Swardfager W, Liu H, Sham L, Reim EK, Lanctôt KL: A meta-analysis of cytokines in major depression. Biol Psychiatry 2010; 67(5):446-457.https://doi.org/10.1016/j.biopsych.2009.09.033.

39. Grivennikov SI, Karin M: Inflammatory cytokines in cancer: tumour necrosis factor and interleukin 6 take the stage. Ann Rheum Dis 2011; 70 Suppl 1:i104-108.https://doi.org/10.1136/ard.2010.140145.

\section{Figures}


5734 individuals met more than one criterion for exclusion:

458 Younger than 45

222 No answers for the questions on the physician-diagnosis cancer

$207 \mathrm{Had}$ been diagnosed with cancer at baseline

2435 With incomplete information on depressive symptoms

4173 Missing data on BMI, education level, smoking and drinking habits, history of diabetes, dyslipidemia, chronic kidney disease, hypertension

11974 Participants included in the final analysis

\section{Figure 1}

Flow chart of sample selection.
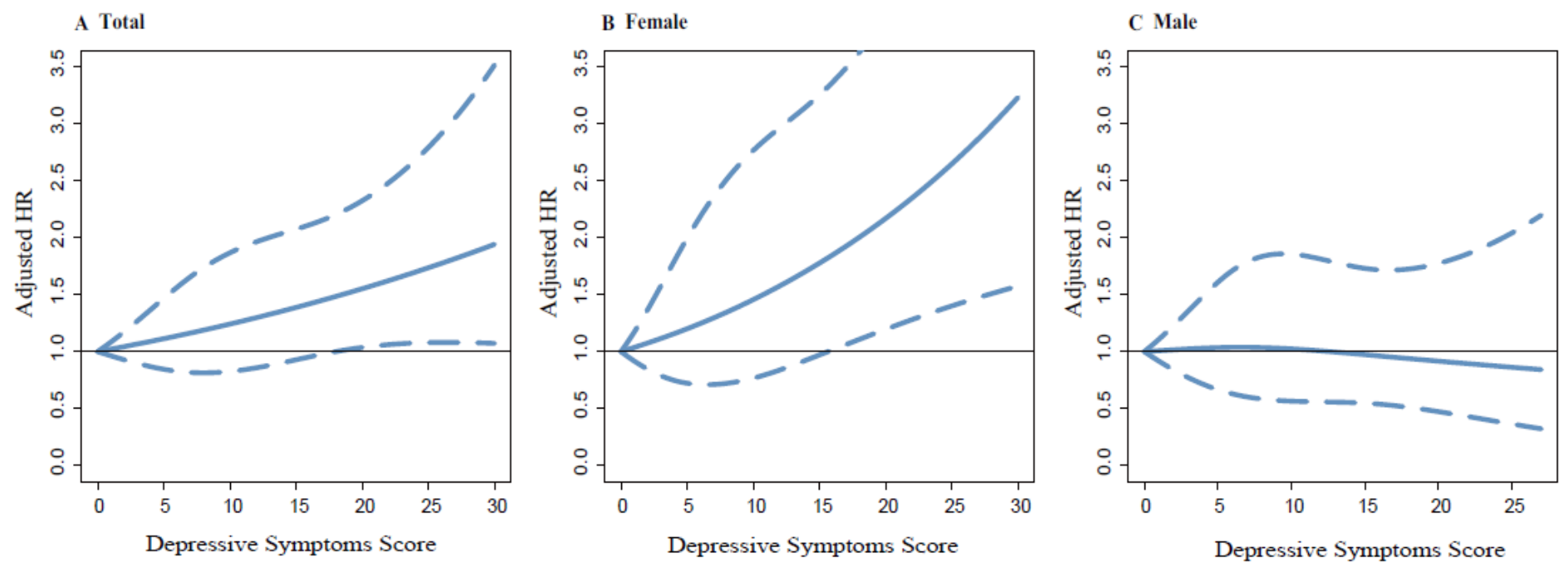

\section{Figure 2}

Adjusted hazard ratios (HRs) of cancer risk, according to CES-D score. The Cox model was adjusted for age, sex, residence, marital status, educational level, smoking, alcohol drinking, body mass index, history of diabetes, hypertension, dyslipidemia and chronic kidney disease. The CES-D score ranges from 0 to 30, with the highest score representing the highest risk of depressive symptoms. Solid lines indicate HRs, and dashed lines indicate $95 \%$ Cls. 

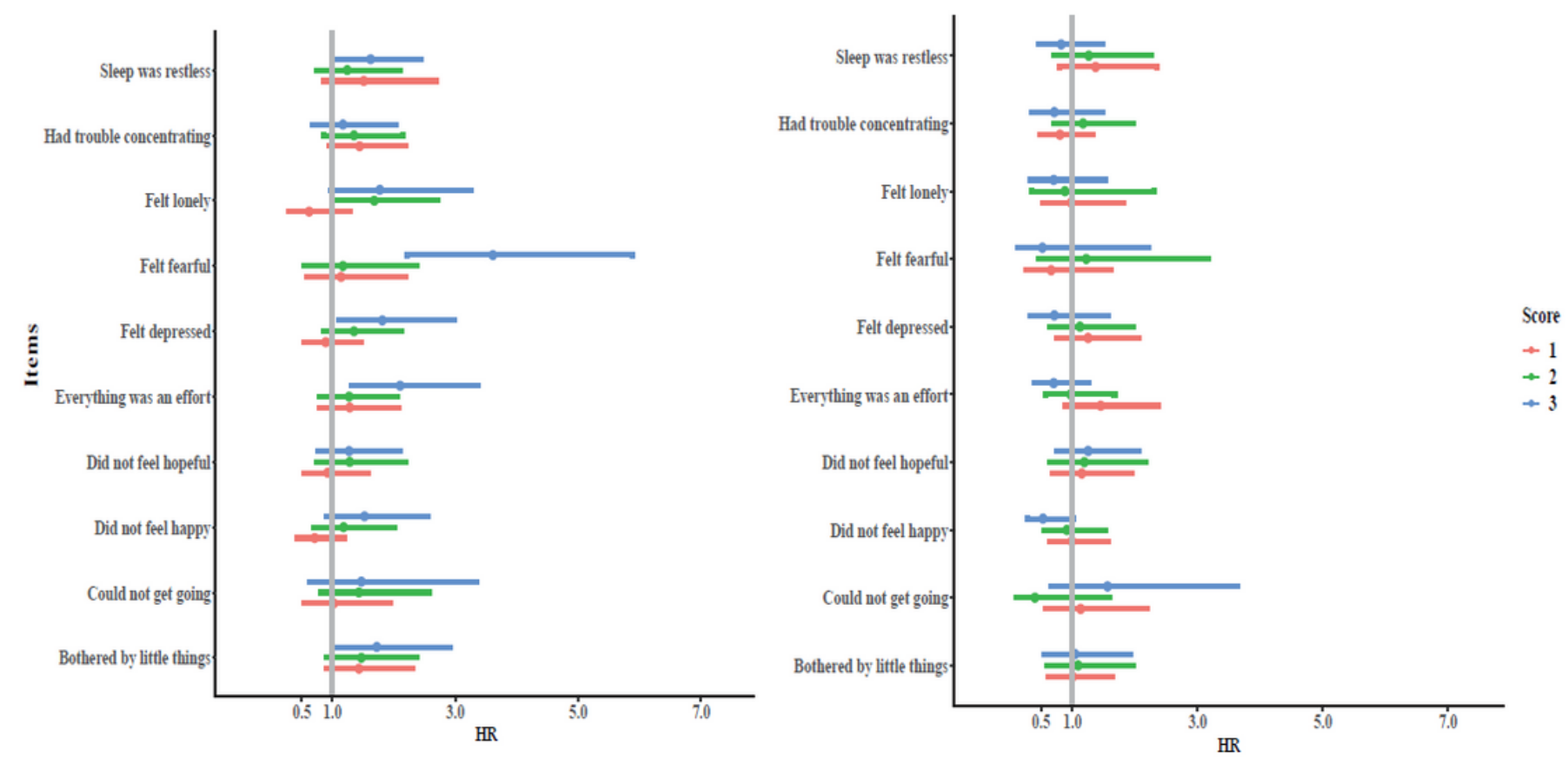

\section{Figure 3}

Association Between Specific Depressive Symptoms and cancer risk The Cox model was adjusted for age, sex, residence, marital status, educational level, smoking, alcohol drinking, body mass index, history of diabetes, hypertension, dyslipidemia and chronic kidney disease. The specific depressive symptoms ranged from 0 to 3 , with higher scores indicating greater depressive symptoms. All estimates accounted for complex survey designs.

\section{Supplementary Files}

This is a list of supplementary files associated with this preprint. Click to download.

- SupplementaryMaterial.docx 